\title{
Knowledge, attitudes and practices regarding milk powder usage among mothers of 1-5 year old children in Pitakotte MOH area
}

\author{
W I Gankanda ${ }^{1}$, I A G M P Gunathilake ${ }^{1}$, S Weliange ${ }^{2}$, V P Wickramasinghe ${ }^{3}$
}

Sri Lanka Journal of Child Health, 2011; 40 (3): 111-115

DOI: http://dx.doi.org/10.4038/sljch.v40i3. 3508

\section{Abstract}

Introduction: Early childhood nutrition plays an important role in growth and development of children. However, due to false beliefs of parents, undue prominence has been given to milk in the child's diet.

Objective: To assess the knowledge, attitudes, practices and factors related to milk powder usage among mothers of 1-5 year old children.

Method: A cross sectional study was carried out among 187 mothers of 1-5 year old children in five randomly selected weighing centres in Pitakotte $\mathrm{MOH}$ area using an interviewer administered questionnaire. Scores were given to knowledge, attitudes and practice.

Results: The mean age of the children was 32 (SD 16.3) months. Mothers' knowledge on milk/milk powder and their usage was good in $20 \%$ and level of attitudes was good in 55\%. Parents received information regarding milk powder from doctors (42.4\%) and TV advertisements (36.5\%). The commonest factor mothers considered when selecting a milk powder was the brand name $(69.7 \%)$. Mean age of initiating cow's milk was 13.5 (SD 9.2) months. Forty seven percent selected a single brand to start feeding their children. At the time of conducting the survey, $47 \%$ were using one particular brand of full cream. While $52.8 \%$ gave concentrated milk, $33.7 \%$ gave diluted milk. One hundred and one (62\%) used a cup while $44(27 \%)$ used a bottle to give milk. Sixty (36.8\%) mothers were giving the correct volume of milk, while 95 $(58.3 \%)$ gave more than recommended. There was a statistically significant association between social class and level of practice $\left(\chi^{2}=5.19 ; \mathrm{p}<0.05 ; \mathrm{df}=1\right)$. Practice was not significantly associated with mother's level of attitudes, knowledge, age, education, parity or the sex of the child.

${ }^{1}$ Medical Student, ${ }^{2}$ Lecturer, Department of
Community Medicine, ${ }^{3}$ Senior Lecturer,
Department of Paediatrics, Faculty of Medicine,
University of Colombo.

(Received on 7 May 2010: Accepted after revision on 1 September 2010)
Conclusions: Knowledge and practice regarding milk and milk powder usage among mothers is poor. Mothers of lower social classes have a good level of practice.

(Key words: Knowledge; attitudes; practices; milk powder usage; mothers)

\section{Introduction}

Early nutrition is crucial for adult health. Exclusive breast feeding is recommended up to the completion of six months of age and complementary foods are introduced thereafter. Diet should have adequate amounts of protein, minerals, vitamins and energy to have optimum growth ${ }^{1}$. If they are not provided as required it will result in growth faltering.

Due to numerous reasons, milk and milk powder have been used to provide a major component of nutritional needs of young children ${ }^{2}$. However, there is no supportive data to state that formula feeding is necessary. Two to three servings $(100 \mathrm{ml}$ each) of milk are recommended as a source of calcium and fat for children in 1-5 year age group ${ }^{3}$.

Many studies have been conducted to assess infant feeding practices and mothers' knowledge on infant nutrition. More than $90 \%$ of mothers give formula milk to their infants at the age of nine months ${ }^{4}$. Although full cream milk is recommended after one year of life, people used to give it during infancy. A study conducted in 1989 among Sri Lankan mothers reported that 35\% of infants were on an unmodified formula ${ }^{5}$. Lakspray®, a full cream formula was used by mothers as it was the cheapest formula milk available in Sri Lanka at that time ${ }^{5}$. Maternal education and knowledge, attitudes and practices (KAP) significantly and independently are associated with children's nutritional status. However, to the best of our knowledge, attitudes, knowledge and practices regarding milk powder usage among mothers of preschool children and factors related to them have not been reported in Sri Lanka. 


\section{Objectives}

The objectives of this study are to assess the knowledge, attitudes and practices regarding milk powder usage among mothers of 1-5 year old children and factors related to the practices.

\section{Method}

A descriptive cross sectional study was conducted among 187 mothers of 1-5 year old children at five randomly selected weighing centres in Pitakotte (Colombo district) $\mathrm{MOH}$ area during the month of July 2009. The ethical review committee of the Faculty of Medicine, Colombo approved the study. Permission from the relevant $\mathrm{MOHs}$ was taken prior to the study.

Data was collected using an interviewer administered questionnaire consisting of sociodemographic data of mothers and children and knowledge, attitudes and practices of the mothers on milk powder usage.

Scores were given to knowledge, attitudes and practices separately. The knowledge score was dichotomized and a score of 0-10 was considered as poor knowledge while a score of 11-18 was considered as good knowledge. Attitude was considered to be negative if score was $0-3$ and positive if it was 4-7. In evaluating practice, a score above 4 points was taken as the minimum desired level for correct practice; thereby a score of 0-4 was considered as unsatisfactory level of practice and 5-6 as correct level of practice.

Social class of the mothers was determined by considering fathers' educational level, occupation and income. Classes 1,2 and 3 were considered as higher classes and 4 and 5 as lower classes ${ }^{6}$.

Correct dilution of milk powder at reconstitution was based on manufacturer's instructions. Any amount less than recommended was considered as over-dilution and more than recommended as overconcentration.

Data was analyzed using SPSS version 15 computer package for Windows.

\section{Results}

Two hundred and thirty one mother-child pairs were invited and 187 (81\%) consented to participate. The mean age of the mothers studied was 31 (SD 5.6) years. Table 1 shows the sociodemographic features of the study population. Majority of the study sample consisted of Sinhalese $(92.5 \%)$ mothers. Although majority of the mothers were unemployed $(91 \%), 64 \%$ had studied up to
GCE $(\mathrm{O} / \mathrm{L})$. The mean number of children in the families was 2 (SD 2). The mean age of the children who participated in the study was 32 (SD $16.3)$ months. There were 106 (56.7\%) boys.

Seven $(3.7 \%)$ mothers thought the suitable age to start formula milk was under six months of age while $131(63.7 \%)$ knew it was above one year of age. However, $12(6.4 \%)$ mothers did not know the suitable age at which formula milk should be started. One hundred (53.5\%) did not know the correct amount of milk needed to be given to a child. Eighty percent of mothers scored less than 10 marks on the 'knowledge score' indicating poor overall knowledge regarding milk/milk powder.

One hundred and nineteen (63.2\%) mothers thought that milk is essential for all babies above one year. Sixty $(37 \%)$ mothers preferred milk powder to fresh milk. Ninety one $(48.6 \%)$ believed milk powder caused 'phlegm' while 84 (45\%) believed fresh milk caused 'phlegm'. Thirteen (7.5\%) mothers believed milk gave all the essential nutrients to the child. Forty $(21.3 \%)$ mothers believed that poor growth was an indication to purchase expensive milk powder. Thirty five percent of mothers believed that expensive milk powders are more nutritious.

Table 1

Sociodemographic data of mothers $N=187$

\begin{tabular}{|l|c|}
\hline \multicolumn{1}{|c|}{ Sociodemographic data } & Number (\%) \\
\hline Nationality of mothers & $173(92.5)$ \\
Sinhalese & $07(3.7)$ \\
Tamil & $05(2.7)$ \\
Muslim & $02(1.1)$ \\
Malay & \\
\hline Mothers' occupation & $170(90.9)$ \\
Unemployed & $03(1.6)$ \\
Unskilled & $06(3.2)$ \\
Skilled & $08(4.3)$ \\
Professional & \\
\hline Mother's level of education & $02(01)$ \\
No school education & $21(11.2)$ \\
Up to year 5 & $120(64.2)$ \\
year 6 to O/L & $39(20.9)$ \\
Up to A/L & $05(02.7)$ \\
Higher Education & $18(09.6)$ \\
\hline Family income (Rs. per month) & $60(32.1)$ \\
$<5000$ & $83(44.4)$ \\
5001- 10,000 & $26(13.9)$ \\
10001-20,000 & \\
>20,000 & $0(0.0)$ \\
\hline Social classes & $05(02.7)$ \\
Class1 & $37(19.8)$ \\
Class 2 & $30(16.0)$ \\
Class 3 & $115(61.5)$ \\
Class 4 &
\end{tabular}


Fifty five percent of mothers had a positive attitude towards usage of milk powder. The sources of information and factors considered in choosing a milk powder brand are given in Tables 2 and 3 respectively.

Table 2

Sources of information considered when choosing a brand $(n=165)$

\begin{tabular}{|l|c|}
\hline \multicolumn{1}{|c|}{ Source } & Number (\%) \\
\hline Doctors & $70(42.4)$ \\
\hline Public health midwife & $36(21.8)$ \\
\hline TV advertisements & $60(36.4)$ \\
\hline Radio advertisements & $13(07.9)$ \\
\hline Newspapers advertisements & $24(14.5)$ \\
\hline Other mothers & $59(35.8)$ \\
\hline Family members & $35(21.2)$ \\
\hline Sales reps & $06(03.6)$ \\
\hline Own experience & $40(24.2)$ \\
\hline
\end{tabular}

Table 3

Factors considered in selecting milk powders $(n=165)$

\begin{tabular}{|l|c|}
\hline \multicolumn{1}{|c|}{ Factor } & Number (\%) \\
\hline Brand name & $115(69.7)$ \\
\hline Price & $63(38.2)$ \\
\hline Packet appearance & $14(08.5)$ \\
\hline Doctor's opinion & $63(38.2)$ \\
\hline Offers/ rewards & $18(10.9)$ \\
\hline Country of origin: Local & $17(10.3)$ \\
& $12(07.3)$ \\
\hline Dissolving easily & $47(28.5)$ \\
\hline Added nutrients & $42(25.5)$ \\
\hline Taste & $59(35.8)$ \\
\hline Child's preference & $52(31.5)$ \\
\hline
\end{tabular}

Individual mothers had received information from multiple sources and many factors had influenced their decision on selecting a milk powder brand. Of the 187 mothers recruited, 169 had started to give formula milk/fresh milk. Four children were given fresh milk. However, two mothers had discontinued giving formula milk at the time of conducting the research as children refused to take. Ages at which formula milk was started are shown in table 4.

Table 4

Practice regarding initiation of milk among mothers

\begin{tabular}{|l|c|}
\hline \multicolumn{1}{|c|}{ Practice } & Number (\%) \\
\hline Age of initiating milk $(N=187)$ & $18(09.6)$ \\
Not yet started & $10(05.3)$ \\
6 months or less & $39(20.9)$ \\
$7-11$ months & $78(41.7)$ \\
$12-17$ months & $20(10.7)$ \\
$18-23$ months & $17(09.1)$ \\
$24-35$ months & $05(02.7)$ \\
36 months or more & \\
& \\
\hline Form of milk initiated $(N=169 *)$ & $165(97.6)$ \\
Milk powder & $04(02.4)$ \\
Fresh milk & *18 children not taking milk powder were excluded
\end{tabular}

The mean age of initiating milk was 13.45 (SD $9.17)$ months. The 18 children who were not given formula milk had a mean age of 28.6 (range 2441 months). Practices of reconstitution of milk of the 163 mothers currently using powdered milk are given in Table 5.

Table 5

Practice of reconstitution and consumption of milk $N=163$ *

\begin{tabular}{|c|c|}
\hline Reconstitution & Number (\%) \\
\hline $\begin{array}{l}\text { Type of spoon used to measure: } \\
\text { teaspoon } \\
\text { tablespoon } \\
\text { spoon supplied in the packet } \\
\text { spoon supplied in another milk powder packet }\end{array}$ & $\begin{array}{l}117(71.8) \\
19(11.7) \\
15(09.2) \\
12(07.4)\end{array}$ \\
\hline $\begin{array}{l}\text { Dilution of milk powder } \\
\text { Correct } \\
\text { Over diluted } \\
\text { Over concentrated }\end{array}$ & $\begin{array}{l}22(13.5) \\
55(33.7) \\
86(52.8)\end{array}$ \\
\hline $\begin{array}{l}\text { Frequency } \\
\text { Once a day } \\
\text { Twice a day } \\
\text { Thrice a day }\end{array}$ & $\begin{array}{l}14(08.6) \\
109(66.9) \\
40(24.5)\end{array}$ \\
\hline $\begin{array}{l}\text { Added ingredients at reconstitution } \\
\text { Sugar } \\
\text { Tea } \\
\text { Chocolate flavours } \\
\text { Malted milk }\end{array}$ & $\begin{array}{l}145(89.0) \\
73(44.8) \\
04(02.5) \\
10(06.1)\end{array}$ \\
\hline
\end{tabular}

*2 children who were given milk powder had discontinued at the time of collection of data 
Only $13.5 \%$ had read the reconstitution instructions provided by the manufacturer on the packet. Sixty two percent of mothers were using the cup to give the milk while $27 \%$ were using only the bottle with teat. About $7 \%$ were using both cup and bottle alternatively. Sixty $(36.8 \%)$ mothers were giving the correct volume of milk while $95(57.5 \%)$ gave more than the desired amount.

The average amount spent over milk powder per child per month was Rs. 847.73 (549.42) and it ranged from two hundred to three thousand rupees.

Only four $(2.1 \%)$ mothers in the study population were giving fresh milk to their children. Two were giving half a cup once a day, while the other two were giving one cup daily. Two mothers were adding sugar to the milk and all were using cups to feed their children. Seventy five $(40.1 \%)$ mothers knew cow's milk contained protein and vitamins. Five mothers thought cow's milk is a good source of iron. One hundred and twenty seven $(67 \%)$ and $56(29.9 \%)$ mothers knew other sources of fat, and vitamin D respectively. Mothers' knowledge about the available alternatives to milk varied and they knew yoghurt $121(64.7 \%)$, cheese 109 (58.3\%), butter $61(32.6 \%)$ and curd $20(10.7 \%)$ are the products available in the market. Although milk powder brands claim they could improve growth of children, only about twenty percent believed they were effective.

Commonly used other dairy products were yoghurt $174(93.05 \%)$ and butter 169 (90.37\%). Seventy eight (44.8\%) mothers were adding butter to child's daily diet.

Social class showed a statistically significant association with the practice $\left(\chi^{2}=5.19 ; \mathrm{p}<0.05\right.$; $\mathrm{df}=1$ ). Mother's age, level of attitudes, knowledge on milk powder usage, education, nationality, parity, child's sex, maturity of the child at birth and birth weight did not show significant associations with practice.

\section{Discussion}

Exclusive breast feeding is recommended up to completion of six months of age and is a prime heath education message. However, $3.2 \%$ mothers thought formula milk could be started below six months of age. Sixty three percent of mothers knew that full cream milk should be started after one year which is the current practice.

Mothers' knowledge about the amount of milk that should be given to their child was poor. Furthermore, many mothers believed that milk is a complete food and could even replace a solid meal. Therefore, a lot of emphasis has been given to milk in daily meals of a young child. Many believed that fresh milk leads to developing more 'phlegm' and therefore they should give powdered milk. Poor knowledge on other dairy products has made people purchase more powdered milk as a source of fat, calcium, vitamins A and D. Most of the parents had received advice from medical personnel. Therefore, it is important to educate them (medical personnel) that milk powder is not the only dairy product that can be given to a child but that there are several other dairy products that could fulfill the child's nutrient requirements adequately.

Television commercials played a significant role in selecting the milk powder brand and mothers were selective of some brands based on the belief of having and not having phlegm; this might be largely due to myths handed down by generations.

This study showed that doctors and TV advertisements played a major role in mother's decision on selecting a milk powder brand for their child.

Majority of mothers started full cream milk after one year of age. More than half of the mothers were giving concentrated milk while about one third gave diluted milk. This could be due to lack of knowledge about reconstitution as well as not having the habit of reading food labels and reconstitution instructions. Furthermore, they could be thinking that the underfed child should get some "food" and give them concentrated milk. These figures were different to what was described in a study carried out in Sri Lanka in $1989^{5}$. In that study, the majority were using diluted milk. It is difficult to explain the reason, but authors believe that economic status would have contributed to that practice.

It is recommended to use a cup to feed the child instead of a bottle, but the present study showed that a considerable number of mothers was using only the bottle to give milk which could contribute to poor oral hygiene. In this study 95 (58.3\%) mothers were giving more than the desired amount of milk to their child. This may be due to poor knowledge on correct amount to be given and also having the false belief that milk is a "whole meal".

The prevalence of fresh milk usage was low in this community where only $2.1 \%$ of mothers were giving fresh milk to their children. Probably this could be due to the interruption in supply of fresh milk in the area and also to false beliefs such as powdered milk being more nutritious due to nutrients that are added and that fresh milk consumption increases 'phlegm'. 
There is a statistically significant association between social class and the level of practice where low classes are having favourable practices. It is contrary to what was expected. Absence of significant association between level of education and level of practice is compatible with the outcome of a study done in India ${ }^{7}$.

The limitations of the study included an inability to obtain a totally representative sample of mothers of all socioeconomic backgrounds, as many mothers were employed and economically stable people were not attending public weighing centres.

\section{Conclusions and recommendations}

- Mothers in the Pitakotte $\mathrm{MOH}$ area have many misconceptions regarding the use of cow's milk and its products.

- Although the majority started to give formula milk at the correct age, they were not reconstituting them properly and gave it an undue prominence in their daily meal. Usage of fresh cow's milk is very low and advertisements had been playing a major role in determining the selection of the milk powder.

- While incentives are being provided to milk producers, there should be programmes to educate the public to increase fresh milk consumption. Therefore, it is time that the medical fraternity takes steps to educate the public about the use of fresh cow's milk and its products such as curd/yogurt more extensively.

\section{References}

1. Wickramanayake TW. Nutrition throughout the life cycle. Colombo: Sri Devi Printers (Pvt) Ltd, Sri Lanka. 2007: p56-58.

2. Wickramanayake TW. Milkfood and nutrition. 3rd ed. Hector Kobbekaduwa Agrarian Research and Training Institute, Sri Lanka. 1996: p183-93.

3. Food based dietary guidelines. Ministry of Health and Nutrition, Sri Lanka. 2003.

4. Nandasena YLS, De Silva C. Infant feeding practice at nine month of age. Abstract book of 122nd Annual Scientific Sessions SLMA. Ceylon Medical Journal.2008; 52(45):24.

5. Warnasuriya D. Pattern of infant feeding in the latter part of the infancy. Ceylon Medical Journal 1989; 34 (24):191-4.

6. Barker DJP, Bennet FJ. Some important epidemiological variable and attitudes. Practical epidemiology. 3rd ed. New York. Churchill Livingstone; 1982. p. 60-61.

7. Gupta MC, Melhotra M, Arora S, Saran M. Relation of childhood malnutrition to parental education and mothers' nutrition related KAP. Indian Journal of Paediatrics 1991; 58 (34):269-74. 